\title{
Klasifikasi Ciri Suara Manusia Berbasis Matlab Menggunakan Metode Fast Fourier Transform
}

\author{
Hafizh Muhammad Arkaan ${ }^{1}$, Ilham Fauzi ${ }^{2}$, Latif Windar Al Rosyid ${ }^{3}$, Apri Junaidi ${ }^{4}$ \\ Fakultas Teknologi Industri dan Informatika, Institut Teknologi Telkom Purwokerto
}

Jln. D.I Panjaitan No 128, Purwokerto, Jawa Tengah, Indonesia

\author{
${ }^{1} 15102019 @$ st3telkom.ac.id \\ ${ }^{2} 15102021 @$ st3telkom.ac.id \\ 315102022@st3telkom.ac.id \\ ${ }^{4}$ aprijunaidi@ittelkom-pwt.ac.id
}

accepted on 23-09-2019

\begin{abstract}
Suara merupakan salah satu bentuk komunikasi yang dapat dilakukan oleh manusia. Manusia memiliki kemampuan untuk membedakan identitas seseorang yang mereka kenal, hal tersebut dikarenakan setiap manusia memiliki ciri atau karakteristik suara yang berbeda antara satu dengan yang lainnya. Pengenalan Suara dibedakan menjadi dua jenis, yaitu verifikasi suara dan identifikasi suara. Verifikasi suara menentukan subjek suara, (apakah suara yang di dengarkan merupakan suara seseorang yang dikenali). Sedangkan identifikasi suara menentukan secara spesifik identitas pembicara.Pada sinyal suara terdapat banyak parameter yang perlu diperhatikan, mulai dari parameter yang bersifat subjektif seperti logat yang dihasilkan, dan dialek yang digunakan, maupun parameter yang ersifat objektif (dapat diukur secara akustik). Permasalahan yang diadapi adalah bagaimana cara mengekstrasi ciri dari sinyal suara yang kompleks sehingga menghasilkan data baru yang lebih praktis tanpa menghilangkan karakteristik sinyal suara tersebut. Parameter yang digunakan dalam penelitian ini adalah frekuensi, amplitudo, dan delay, menggunakan metode Fast Fourier Transform untuk mengenali suara pria dan wanita berdasarkan dialek.
\end{abstract}

Keywords: Amplitudo, Delay, FFT, Frekuensi, Pengenalan Suara

\section{INTRODUCTION}

$\mathbf{P}$ ada zaman modern sekarang ini teknologi informasi sudah semakin pesat berkembang, Setiap peralatan elektronik saat ini sudah menggunakan sinyal untuk mengirim dan menerima data. Salah satunya adalah sinyal suara. Sinyal suara banyak digunakan dalam berbagai aspek kehidupan seperti berkomunukasi, recording, sound effect, voice recognition seperti pada [1][2][3][4][5][6]dan lain sebagainya.

Dalam pengenalan atau identifikasi terhadap suara manusia, tidak semua pendengaran manusia mampu membedakan suara dari masing-masing individu yang dikenalnya[7]. Kepekaan telinga menjadi salah satu faktor terhadap penilaian terhadap proses pengenalan suara karena keterbatasan sensitivitas telinga manusia terhadap amplitudo suara asal serta dialek yang diucapkan terdengar asing.

Untuk mengatasi permasalahan tersebut masalah tersebut, maka dilakukanpenelitian ini yang bertujuan untuk mensimulasikan pengenalan suara berdasarkan frekuensi, amplitude dan delay serta dialek yang 
diucapkan. Cara mengolah sinyal suara, nantinya bisa digunakan dalam sebuah microphone agar nantinya sinyal suara yang didapat lebih stabil dan kuat sehingga minim gangguan sehingga ciri suara bisa didapatkan secara jelas.

Proses dan perancangan program dalam simulasi ini dikerjakan melalui aplikasi MATLAB. Dalam proses pemfilteran sinyal pada sistem ini menggunakan metodeFast Fourier Transform (FFT) sebagai metode yang mentransformasikan sinyal suara dalam domain waktu (s) menjadi sinyal suara dalam domain frekuensi (Hz).

\section{LITERATURE REVIEW}

Penelitian tentang "Sistem Pengolahan Suara” Menggunakan Algoritma FFT (Fast Fourier Transform) yang dilakukan oleh Harun Sujadi dkk menghasilkan suatu sistem pengolahan suara nantinya bisa digunakan untuk mengetahui frequency suara dari sejumlah orang yang berbicara. Output yang dihasilkan adalah frequency FFT suara, gelombang suara dan sederetan nilai fungsi waktu diskrit [8].

Penelitian tentang "Sistem Pengenalan Penutur" menggunakan Metode Mel-frequency Wrapping yang dilakukan Ali Mustofa menghasilkan sistem pengenalan penutur. Dalam pengenalan suara penutur, distorsi diukur berdasarkan minimisasi jarak Euclidean yang digunakan saat mencocokkan (matching) penutur tak dikenal dengan database penutur [1].

Penelitian tentang “Sistem Identifikasi Suara Pria Dan Wanita Berdasarkan Usia” Menggunakan Mel Frequency Cepstral Coefficient Dan LPC Dengan Metode Klasifikasi SOM yang dilakukan oleh Septya Erani dkk menghasilkan sistem pengenalan suara menggunakan parameter akustik yang sifatnya lebih objektif, dengan menggunakan metode ekstraksi ciri Mel-Frequency Cepstral Coefficient (MFCC) dan Linear Predictive Coding (LPC). Dalam sistem yang menggunakan metode JST-SOM ini diperoleh akurasi $100 \%$ saat pengujian dengan menggunakan data latih sebagai data uji, sedangkan saat data uji diberikan noise terdapat beberapa hasil akurasi. Sehingga dapat disimpulkan bahwa metode JST-SOM dapat digunakan sebagai salah satu metode pengklasifikasian suaran manusia karena performansinya yang cukup bagus[2]

Penelitian tentang “Klasifikasi Ciri Suara Manusia” Berbasis Matlab Menggunakan Metode Fast Fourier Transform (FFT) Di Politeknik Negeri Balikpapan yang dilakukan oleh silfi fakhirotul rukhyah menghasilkan sistem untuk mengenali suara manusia dengan aplikasi berbasis matlab R2015a. Parameter yang digunakan dalam penelitian adalah amplitudo, frekuensi, delay, dan daya sinyal suara. Sehingga dapat disimpulkan suara pria memiliki daya amplitude yang lebih tinggi dan suara wanita memiliki delay serta kerapatan frekuensi suara yang lebih tinggi dibanding pria.

Penelitian tentang "Identifikasi Sinyal Suara" Berbasis MatlabMenggunakan Metode Fast Fourier Transform (Fft) di Universitas Sumatra Utara yang dilakukan oleh Rut Airin Lamtiur Sibarani menghasilkan Sistem ini akan mencari nilai maksimum untuk setiap sampel suara pada sinyal FFT, kemudian membuat suatu klasifikasi suara agar nantinya dapat teridentifikasi. nilai maksimum dan teks hasil pengenalan suara. Pada program ini, parameter pengenalan terbaik adalah $96 \%$ dalam pengujian secara real time. Sehingga menghasilkan. nilai maksimum sebagai penentu teks suaranya dengan hasil yang ditampilkan berupa plot hasil sinyal FFT, indeks nilai maksimum dan teks suara yang dikenali.

Penelitian tentang "Sistem Pengenalan Penutur" menggunakan MetodeMel-frequency Wrapping di Universitas Brawijaya yang dilakukan Ali Mustofa menghasilkan untuk ekstraksi ciri dari sinyal wicara dan membandingkan dengan penutur tak dikenal dengan penutur yang ada dalam database. Penulis juga menggunakan Vector Quantization untuk menghasilkan ukuran vektor-vektor yang kecil yang berhubungan dengan distribusi centroid. Parameter yang digunakan yaitu algoritma K-Mean yang digunakan untuk klustering. Database wicara menggunakan 10 penutur berbeda dengan MFCC12, 20 codebook, dan 16 centroid.

Penelitian tentang "Simulasi Sistem Pengacak Sinyal" Berbasis Matlab menggunakan Metode FFT (Fast Fourier Transform) di Universitas Ratulangi yang dilakukan oleh Reonaldo Yohanes Sipasulta dkk menghasilkan pengacakan sebuah sinyal suara sehingga informasi yang akan di sampaikan hanya akan 
diterima oleh tujuan yang kita inginkan. sistem ini dapat mengacak semuajenis suara yang direkam dalam interval waktu 3 detik.

\section{RESEARCH METHOD}

Pada penelitian ini terdapat beberapa tahapan yang dilakukan oleh peneliti dalam melakukan penelitian adalah sebagai berikut.

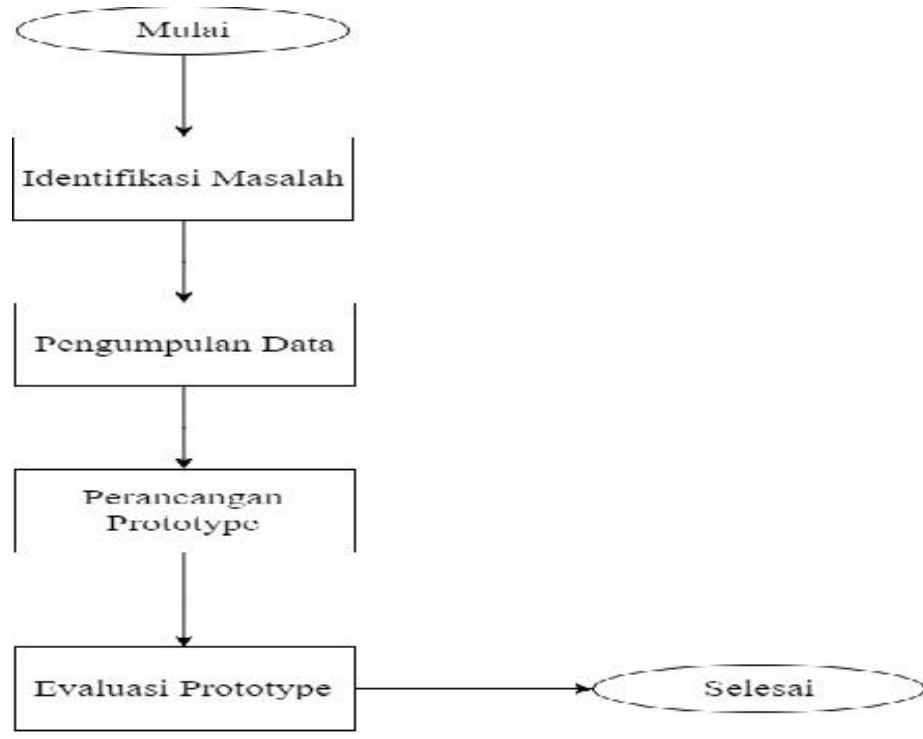

Gambar 1. Tahapan Penelitian

Gambar 1 menunjukkan alur dari tahapan-tahapan penelitian yang dilakukan oleh peneliti, berikut adalah penjelasan dari setiap tahapan-tahapan penelitian tersebut.

\section{Identifikasi Permasalahan}

Pada tahap awal penelitian ini, peneliti menemukan sebuah permasalahan mengenai pengenalan ciri suara pada manusia. Permasalahan yang terjadi pada data suara terletak pada parameter frekuensi, amplitudo peneliti melakukan penelitian dengan tujuan untuk menyelesaikan permasalahan kepekaansuaraterhadap perbedaan tekanan suara dari suara asal sehingga nantinya suara asal dapat dilakukan identifikasi.

\section{Pengumpulan Data}

Data yang dibutuhkan pada penelitian ini adalah berupa data suara hasil rekaman mahasiswa. Media yang digunakan untuk melakukan rekaman adalah melalui laptop. Untuk melakukan perekeman suara dengan cara menulis program di MATLAB. Suara yang sudah direkam kemudian disimpan dalam format wav di folder tertentu. Nantinya hasil rekaman tersebut akan dibaca dengan program di MATLAB untuk diuji.

\section{Kebutuhan Perangkat Keras dan Perangkat Lunak}

Peneliti dalam melakukan penelitian ini menggunakan spesifikasi kebutuhan perangkat lunak dan perangkat keras sebagai berikut:

a. Kebutuhan perangkat lunak

1. Sistem operasi Windows 10 Professional x64 bit

2. Matlab R20016a 
b. Kebutuhan perangkat keras

1. ACER ASPIRE E1 471 ProcessorIntel Core I3 @ 2.2 Ghz x64

2. RAM 8 GB DDR3 1866 Mhz Double Channel

3. Harddisk 1 TB 5400 RPM

\section{Perancangan Prototype dan Penerapan Metode Fast Fourier Transform}

Tujuan dari perancangan prototype ini adalah untuk membuat sebuah program yang memiliki fungsi untuk melakukan identifikasi suara input. Program pada penelitian ini menerapakan perhitungan Fast Fourier Transform untuk menghilangkan noise.

Fast Fourier Transform (FFT) adalah suatu algoritma yang digunakan untuk menghitung transformasi fourier diskrit dengan cepat dan efisien. Persamaan FFT ditunjukkan pada Persamaan 1 dibawah ini.

$$
S(f)=\int_{-\infty}^{\infty} s(t) e^{-j 2 \pi f t} d t
$$

Dimana s(f) adalah sinyal dalam domain frekuensi (frequency domain), $\mathrm{s}(\mathrm{t})$ adalah sinyal dalam domain waktu (time domain), dan adalah konstanta dari nilai sebuah sinyal, f adalah frekuensi dan $t$ adalah waktu.

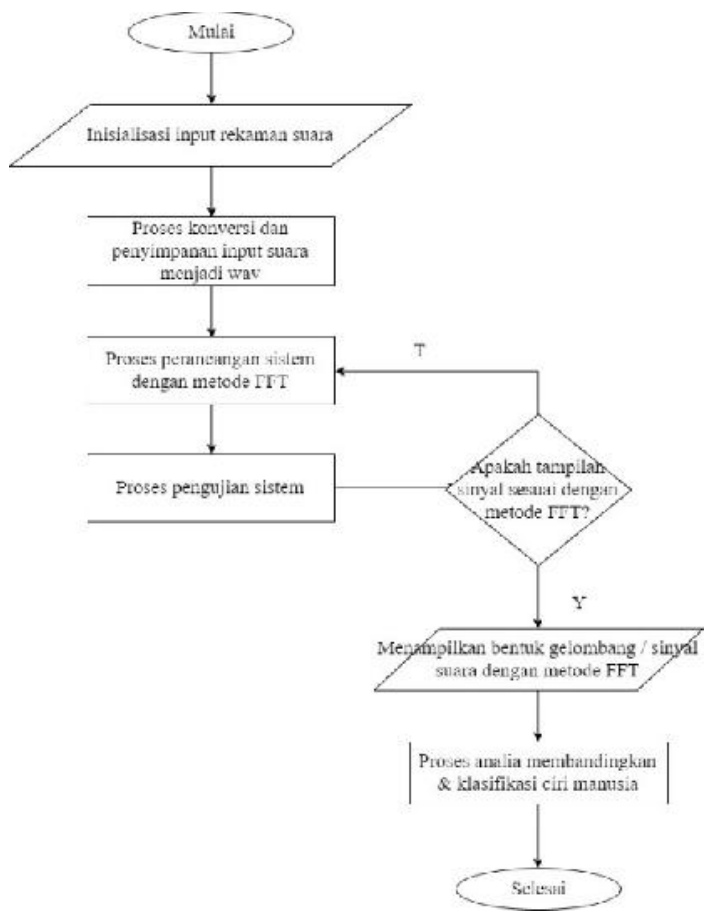

Gambar 2. Diagram Alur Sistem

Alur proses pada sistem diawali dengan inisialisasi input suara, kemudian melakukan perekaman suara menggunakan sistem tersebut. Setelah mendapatkan data suara, selanjutnya data tersebut disimpan di folder tertentu dengan format wav. Data suara hasil rekaman tersebut akan dibaca apakah tampilan sinyal sesuai dengan metode FFTFast Fourier Transform. Dari hasil perhitungan tersebut didapatkan gelombang / sinyal suara Selanjutnya dilakukan proses Analisa dan klasifikasi ciri suara.

\section{Pengujian Prototype}


Setelah prototype dibuat dan dapat digunakan, selanjutnya adalah melakukan pengujian terhadap prototype tersebut. Apabila sistem berjalan dengan baik, maka sistem akan menampilkan sebuah grafik data suara rekaman asli dan data suara hasil dari penerapan metode Fast Fourier Transform untuk mengenali suara.

\section{RESULTS AND DISCUSSION}

Tahapan pertama adalah membuat tampilan gui sinyal suara dengan FFT.

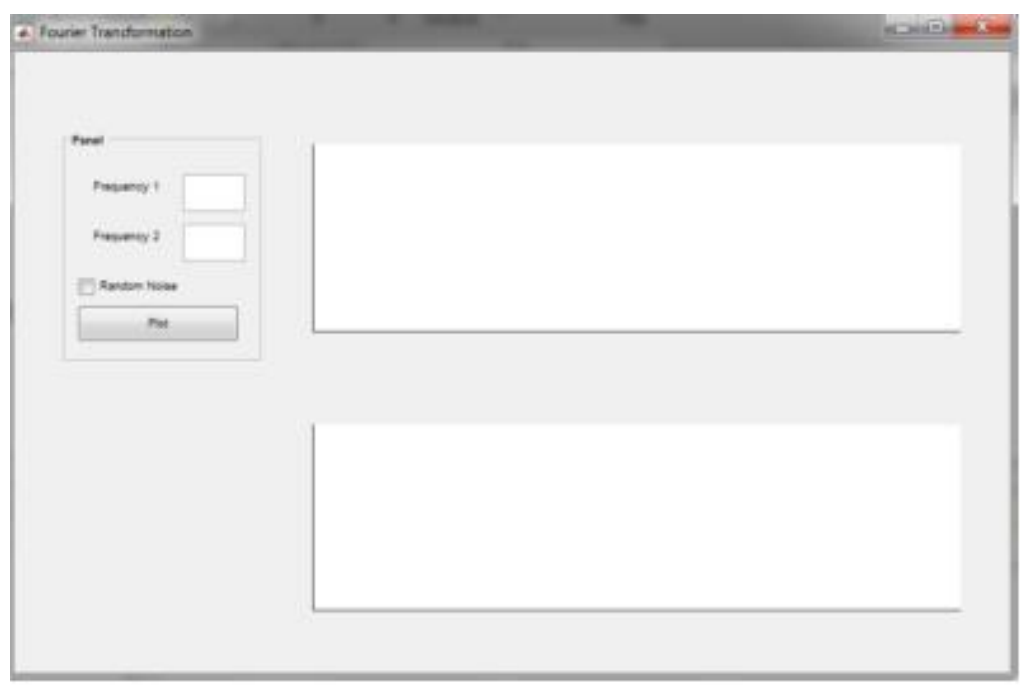

Gambar 3. Tampilan GUI Sinyal Suara

Setelah membuat tampilan GUI maka selanjutnya adalah memproses input sinyal suara mengguanakan FFT.

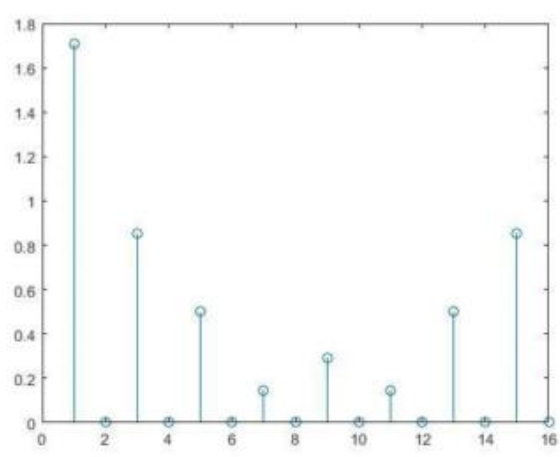

Gambar 4. Memproses Sinyal Dengan FFT

Selanjutnya adalah memproses daya sinyal setelah proses pengujian daya suara dengan FFT. 


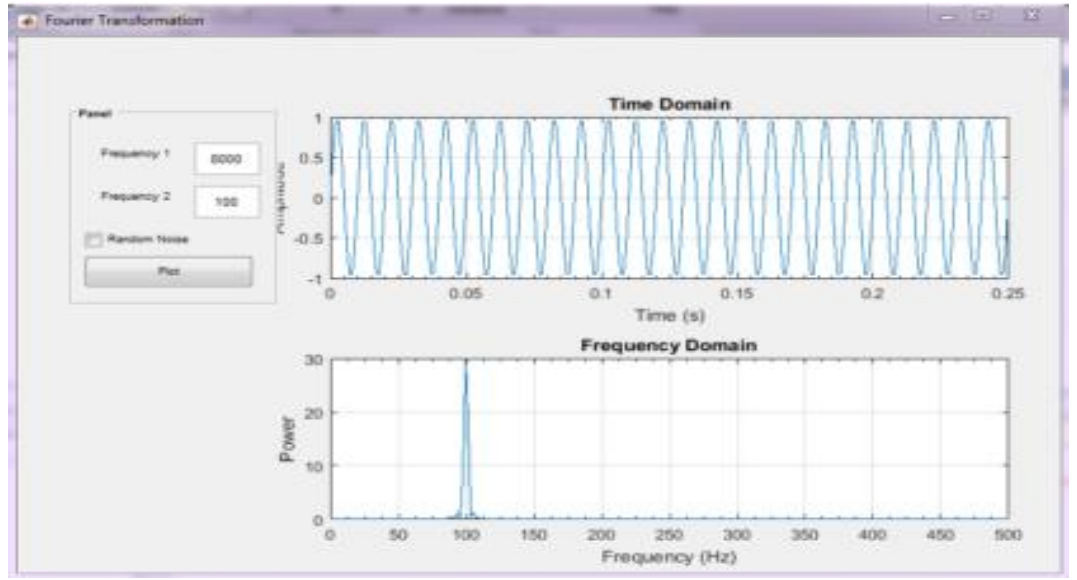

Gambar 5. Pengujian Daya Suara dengan FFT

\section{CONCLUSION}

Berdasarkan pengujian yang telah dilakukan dapat disimpulkan bahwa metode Fast Fourier Transform(FFT) dapat diterapkan untuk melakukan pengenalan suara manusia menggunakan dengan menggunakan parameter yang ada.

Program yang dibuat pada penelitian ini masih sangat sederhana, makadari itu pada penelitian lebi lanjut dapat ditambahkan fitur-fitur yang lebih dapat mengembangkan sistem ini.

\section{ACKNOWLEDGMENT}

Terima kasih sebesar-besarnya untuk Bapak Apri Junaidi, M.Kom., M.Cs selaku dosen mata kuliah Pengenalan Suara yang telah membimbing pada penelitian ini.

\section{REFERENCES}

[1] J. T. Elektro, U. Brawijaya, and A. Mustofa, "Sistem Pengenalan Penutur dengan Metode Mel-frequency Wrapping," J. Tek. Elektro, vol. 7, no. 2, pp. 88-96, 2007.

[2] S. Erani, B. Hidayat, and S. A. Wibowo, "Sistem Identifikasi Suara Pria Dan Wanita Berdasarkan Usia Menggunakan Mel Frequency Cepstral Coefficient Dan LPC Dengan Metode Klasifikasi SOM," in eProceedings of Engineering, 2015.

[3] S. N. Azhari, "BACAAN IQRA MELALUI VOICE RECOGNITION," J. UPNYK, 2014.

[4] P. Studi, T. Multimedia, J. Teknologi, P. N. Lhokseumawe, J. B. A. Km, and P. O. B. O. X. Telpon, "Pengenalan Karakter Suara Laki-Laki Aceh Menggunakan Metode FFT ( Fast Fourier Transform )," $J$. Infomedia, vol. 2, no. 1, pp. 20-24, 2017.

[5] R. A. Lamtiur, "Identifikasi Sinyal Suara Menggunakan Metode Fast Fourier Transform ( FFT ) Berbasis Matlab," Repos. Institusi USU, 2018.

[6] S. B. Bhaskoro, F. Pelatihan, and F. Pengenalan, "Aplikasi pengenalan gender menggunakan suara," vol. 2012, no. Snati, pp. 15-16, 2012.

[7] "Klasifikasi Ciri Suara Manusia Berbasis Matlab Menggunakan Metode Fast Fourier Transform (FFT) Di Politeknik Negeri Balikpapan,” Repos. USU, 2018.

[8] H. Sujadi et al., "Sistem Pengolahan Suara Menggunakan Algoritma FFT (Fast Fourier Transform)," in Prosiding SINTAK 2017, 2017, pp. 101-107. 